\title{
Discover Energy
}

\section{Editorial}

\section{Discover energy inaugural editorial}

\author{
G. R. Tynan ${ }^{1}$
}

Published online: 17 May 2021

(c) The Author(s) 2021 OPEN

The world is in the midst of a transition towards increased average lifespan, literacy rates and education levels, coupled with reduced infant mortality and average family size. This transition began with the onset of industrialization, first realized in Europe, North America, and portions of Asia in the 19th and first half of twentieth centuries, and more recently has taken hold throughout India, China and south Asia and Africa. As these trends continue, by the latter half of this century the large majority, and perhaps all, of the world's human population will likely be able to enjoy these benefits. Furthermore, the changes associated with this transition have historically been associated with a reduction in population growth rates, and thus it is expected that the human population may also stabilize later in the century.

This transition has historically required significant primary energy resources coupled with their conversion into forms that allow humans to modify their environment, manipulate material goods, and move both themselves and those materials and goods around the globe. As a result, the global demand for energy in the form of electricity, transportation fuels, and industrial, commercial and residential heat sources has increased substantially in the past century, and is expected to continue to do so through at least the middle of the 21 st.

In the face of this transition, at the time of writing a significant portion of the world's human population still lacks access to minimal energy resources. This has serious impacts on quality of life for affected individuals, who endure reduced lifespan, lower literacy rates, and unacceptably high infant mortality. For example, millions of people, having no access to fossil fuels and electricity, use biomass in the form of firewood, charcoal or dung as their sole source of energy, primarily for cooking and lighting purposes. This results in the emission of particulates that act as a source of severe indoor air pollution, resulting in millions of premature deaths annually and causing short-lived atmospheric warming, contributing to climate change. Providing access to cleaner energy resources as quickly as possible to the poorest regions of the world thus presents an enormous challenge and opportunity.

Currently, fossil fuels provide the vast majority of the world's industrialized energy demand; given the large-scale investment in fossil-fuel infrastructure, their current market dominance and the scale of the expected increase in global energy demand driven by the demographic transition described above, fossil fuels are expected to continue their dominant role as the leading primary energy source for some significant time into the future. It is also a fact that the combustion of fossil fuels inherently leads to production of $\mathrm{CO}_{2}$ which has historically, simply been emitted into the atmosphere where a portion of it accumulates due to its long atmospheric residence time. Since it also absorbs infra-red radiation, this build-up results in a gradual warming of the Earth. Left unchecked these effects will push the Earth's climate away from the temperate conditions that have persisted for the entirety of human civilization, with unknown and potentially dire consequences for humanity.

The human world is thus built on an energy status quo that is inherently unsustainable. Driven in large part by these considerations, the world energy economy is in the early stages of a profound revolutionary transformation. To a large degree, this revolution will involve the electrification of as much of the economy as possible, coupled with the decarbonization of

G. R. Tynan, gtynan@ucsd.edu| ${ }^{1}$ Mechanical and Aerospace Engineering Department, University of California, San Diego, USA.

Discover Energy $\quad$ (2021) 1:1

| https://doi.org/10.1007/s43937-021-00001-7 
electricity generation by shifting away from coal to natural gas generation along with adoption of zero-carbon alternatives such as hydropower, solar thermal, solar photovoltaic, wind, nuclear-based, and deep-geothermal sources. If the capture and permanent sequestration of $\mathrm{CO}_{2}$ develops into an economically viable choice, then fossil fuel usage could conceivably continue for some decades; otherwise climate change concerns will ultimately force a move away from fossil-fuel generation. Commodity industries such as steel, concrete, plastics, fertilizer, and other chemical production will have to decarbonize either by shifting their processes to use electricity and/or by adoption of new process techniques, and air and sea-based transportation systems will move to net-zero $\mathrm{CO}_{2}$ emission propulsion systems. Finally, depending upon how quickly the energy system is decarbonized and what final $\mathrm{CO}_{2}$ concentration is deemed acceptable, deployment of net-negative emission technologies to remove and sequester $\mathrm{CO}_{2}$ from the atmosphere may also become necessary.

An enormous number of questions emerge as one considers the challenge of this transformation of the human energy system. What are the fundamental science breakthroughs needed to enable and accelerate the development of the requisite clean energy technologies? How do we translate these fundamental breakthroughs into nascent technologies, products and businesses that can gain a foothold in the energy market, begin to compete with incumbents, gain market share, and win a competition that-it is hoped-selects cost-effective and scalable clean energy technologies? What is the best mix of clean energy technologies for adoption in the rich and well developed world? In the more newly developing regions? In the most impoverished regions of the world? How should public and private resources be deployed to finance this work? What are the best policies, incentives/disincentives, and market structures to adopt that would lead to the rapid uptake of clean energy technologies and, at the same time, avoid locking in suboptimal development pathways that do not lead to the requisite deep decarbonization of the entire system?

\section{Aim and scope of the journal}

It is in this context that the new journal Discover Energy is offered. The journal seeks to foster a multi-disciplinary forum focused on all aspects of this transformation-recovery or harvesting of primary energy sources; development and deployment of attractive technologies for their conversion to electricity or other secondary sources; development of energy carriers and storage systems; modeling of transition scenarios and implications for policy and research; energy services and end uses; impact of these energy systems on environment and climate; energy technology transitions, market penetration, diffusion and adoption; relevant business, economic and policy; and implications for deep decarbonization, climate change mitigation, and sustainable development goals.

\section{What this journal offers}

Discover Energy is a broad and inclusive, open-access journal publishing research across all aspects of the energy transformation now underway. In our view, this inclusive ethos of Discover Energy sets it apart from other broad-scope energy journals. By not trying to pre-judge papers, it allows research that may lie outside current paradigms or that crosses interdisciplinary boundaries to be published more easily. Ultimately we believe that this inclusive approach, alongside the speed of its peer review process and being fully Open Access (OA), will allow Discover Energy to have a broader impact on the field and society as a whole by spreading new ideas quickly across multiple and overlapping communities. Finally, by providing a streamlined submission process and a rigorous and rapid review and decision making process within an OA environment, Discover Energy aims to become a well-regarded and impactful venue accessible to all readers - at any location and in any time-who have an interest in accelerating this critical system transformation.

\section{EBM and Associate Editors}

To help in this endeavour, the journal has formed an Editorial Advisory Board, composed of a cross-section of well-known experts from across all relevant domains, to guide choices about key decisions for the journal, including suggestions for timely and impactful special topical collections, review articles, invited articles, and editorials. The Editor-in-Chief and Associate Editors are then tasked with executing the journal's vision and transforming its goals into impactful and thoughtful published works.

The colleagues listed on the website below are part of this effort:

https://www.springer.com/journal/43937/editors 


\section{Topical collection plans}

To help readers to quickly identify research on subject areas of particular interest to them, Discover Energy will publish guest-edited Topical Collections on emerging hot topics of relevance to all aspects of energy research. These will be edited by invited and approved Guest Editors; experts in their fields who will determine the scope of the collection and be involved in soliciting papers to ensure the diversity and breadth of the published research, as well as managing the papers through the peer-review process.

All manuscripts submitted to a Topical Collection will be assessed according to the standard Discover Energy editorial criteria and are subject to all standard journal policies.

G.R. Tynan, Founding Editor-in-Chief.

Open Access This article is licensed under a Creative Commons Attribution 4.0 International License, which permits use, sharing, adaptation, distribution and reproduction in any medium or format, as long as you give appropriate credit to the original author(s) and the source, provide a link to the Creative Commons licence, and indicate if changes were made. The images or other third party material in this article are included in the article's Creative Commons licence, unless indicated otherwise in a credit line to the material. If material is not included in the article's Creative Commons licence and your intended use is not permitted by statutory regulation or exceeds the permitted use, you will need to obtain permission directly from the copyright holder. To view a copy of this licence, visit http://creativecommons.org/licenses/by/4.0/.

Publisher's Note Springer Nature remains neutral with regard to jurisdictional claims in published maps and institutional affiliations. 